\title{
Direct pre-differentiation of rat mesenchymal stem cells into dopaminergic cells
}

\author{
Judith Zavala-Arcos ${ }^{1}$, Maria Teresa Gonzalez-Garza ${ }^{1^{\star}}$, Janet Gutierrez-Alcala $^{1}$, \\ Hector R. Martinez ${ }^{2}$, Jorge E. Moreno-Cuevas ${ }^{1}$ \\ ${ }^{1}$ Servicio de Terapia Celular, School of Medine and Health, CITES, Tecnológico de Monterrey, Monterrey, México; \\ *Corresponding author: mtgonzalezgarza@itesm.mx \\ ${ }^{2}$ Servicio de Neurologia, Hospital San José Tec de Monterrey, Monterrey, México
}

Received 19 February 2013; revised 25 March 2013; accepted 15 April 2013

Copyright (C) 2013 Judith Zavala-Arcos et al. This is an open access article distributed under the Creative Commons Attribution License, which permits unrestricted use, distribution, and reproduction in any medium, provided the original work is properly cited.

\begin{abstract}
The use of stem cells has been proposed as an alternative treatment for certain neurodegenerative disorders. It has also been suggested that in the pre-differentiated state, stem cells might provide a better therapeutic option than cells that are undifferentiated or fully differentiated. The purpose of this study was to develop a protocol aimed at reducing the incubation time required to induce the conversion of rat mesenchymal stem cells into immature dopaminergic neurons. Stem cells obtained from rat bone marrow were incubated in a control or induction media for 2 - $24 \mathrm{~h}$. Cells incubated for $24 \mathrm{~h}$ in induction medium demonstrated an increase on the levels of the neuronal protein markers nestin, glial fibrillary acid protein, and $\beta$-tubulin III, as well as increases in the expression of Pax3, EN1, Thy1.1, and GEF10 genes. This manuscript presents evidence that adult mesenchymal cells are capable to respond, in a short time period, to a neuroinduction medium, and give raise to predifferentiated neuron like cells representing an alternative for Parkinson disease cell therapy transplantation.
\end{abstract}

Keywords: Cell Differentiation; Dopamine Producing Cells; Neuro-Differentiation; Parkinson's Disease; Stem Cells

\section{INTRODUCTION}

Parkinson disease is a major neurodegenerative disease of the nervous system. It is characterized by motor disability as a consequence of nigral neuronal death [1]. Pharmacological correction of the brain dopamine deficit constitutes the first line of treatment for affected patients.
Unfortunately, this therapy does not stop the progression of the disease. Other treatment options include deep surgical brain stimulation [2]. Cell therapy has been proposed as an alternative for treatment of this neurodegenerative disorder due to the fact that significant clinical signs are caused by specific and selective loss of nigrostriatal dopaminergic neurons. The possibility of replacing those cells has been explored through the transplantation of embryonic stem cells (ESCs), fetal stem cells, induced pluripotential stem cells (iPSCs), and mesenchymal stem cells (MSCs) in animal models. Of these, ESCs proved to be capable to differentiate into dopaminergic neurons, after transplantation into the striatum in Parkinson disease rat models [3-6]. Human clinical trials reported variable responses; in patients implanted with ESCs into the putamen, significant clinical improvements were observed based on standardized tests for Parkinson disease [7]. Improvements have been assessed in human subjects by either evaluations in their motor function, or by the reduction of daily L-dopa dosing [8-9]. However, this approach has not been widely accepted. Besides ethical concerns, a large amount of tissue is needed for each patient, because only $3 \%-20 \%$ of transplanted cells survive [10-12].

Reprogramming somatic cells to pluripotency gives the opportunity to obtain iPSCs as a viable alternative for cell therapy in patients with Parkinson disease [13-15]. Although important results have been obtained with ESCs, fetal stem cells and iPSCs, these cells present ethical and genetic problems that need to be fully addressed before they could be considered for clinical application.

On the other hand, MSCs do not present any of those ethical concerns. To prove its possible efficacy as an alternative treatment for Parkinson disease, several studies have been performed in an animal model. Results showed that grafted undifferentiated human MSCs exerted neuroprotective effects against nigrostriatal degen- 
eration induced by 6-hydroxydopaminehydrobromide (6OHDA), but did not transform into functional dopaminergic neurons [16,17].

Although MSCs do not present ethical concern, it has been reported that prolonged in vitro culture could increased genetic and epigenetic abnormalities, therefore, it is important to consider their use on the first passages [18]. The general aim of this study was to develop a protocol to induce rat bone marrow MSCs conversion into immature neural dopaminergic-like cells in short time periods.

\section{METHODS}

\subsection{Ethics Statement}

Animal studies were performed after approved by the Animal Ethics Committee from the Medical School at the "Instituto Tecnológico y de Estudios Superiores de Monterrey” (ITESM), Reg. 2009-Re-001. All surgeries performed in the animals were under anesthesia and all efforts were made to minimize animal suffering. Animals were housed five per cage at $20^{\circ} \mathrm{C}-22^{\circ} \mathrm{C}$ on a $12 / 12 \mathrm{~h}$ light/dark cycle, with food and water ad libitum.

\subsection{Mesenchymal Cell Isolation and Culture}

MSCs were obtained from adult male Wistar rats, weighing 220 g. Hank's balanced salt solution (Gibco, Grand Island, NY) was used to extrude the bone marrow from femurs and the suspension was filtered using a 70 $\mu \mathrm{m}$ pore size cell strainer (BD Falcon, Bedford, MA). After centrifugation, cells were resuspended in Dulbecco's modified Eagle's medium (DMEM-F12; Gibco) containing 20\% fetal bovine serum (FBS; Gibco) and 1\% antibiotics (streptomycin-penicillin) (Gibco). Cells were seeded in $100 \mathrm{~mm}$ culture dishes (Corning Inc., New York, NY) at $37^{\circ} \mathrm{C}$ and $5 \% \mathrm{CO}_{2}$ in a humid chamber for $24 \mathrm{~h}$. To remove nonadherent cells, cultures were washed with phosphate-buffered saline (PBS; $\mathrm{pH}$ 7.4) and the culture medium was replaced with DMEM-F12 containing $10 \%$ FBS and $1 \%$ antibiotics.

\subsection{Control Medium (CM)}

Before induction, cells on their fourth passage were placed in DMEM-F12 containing 5\% FBS and 1\% antibiotics for $24 \mathrm{~h}$, which was used as the CM. Cells were then washed with PBS (pH 7.4) and the medium was replaced with induction medium (IM).

\subsection{Induction Medium (IM)}

IM consisted of CM plus 0.1 $\mu \mathrm{M}$ RA (Sigma-Aldrich, St. Louis, MO), $1 \mathrm{mM} \beta$-mercaptoethanol (Sigma-Aldrich), $2 \mathrm{mM}$ glutamine (Invitrogen, Grand Island, NY), $10 \mathrm{ng} / \mathrm{mL}$ fibroblast growth factor 8 (FGF8) (Sigma-
Aldrich), 0.2\% dimethyl sulfoxide (Sigma-Aldrich), 40 $\mathrm{ng} / \mathrm{mL}$ of epithelial growth factor (Invitrogen), $0.5 \mathrm{mM}$ 3-isobutyl-1-methylxanthine (Sigma-Aldrich), $5 \mu \mathrm{g} / \mathrm{mL}$ insulin-transferrin-selenium (Gibco), $2 \mu \mathrm{g} / \mathrm{mL}$ heparin (Pisa, Guadalajara, Jal, Mexico), 10 ng/mL brain-derived neurotrophic factor (Invitrogen), $4.5 \mathrm{mg} / \mathrm{mL}$ glucose (Sigma-Aldrich) and $10 \mathrm{ng} / \mathrm{mL}$ of sonic hedgehog (SHH) protein (R\&D Systems, Minneapolis, MN).

\subsection{Immunocytochemistry}

Circular glass slides treated with poly-L-lysine (Sigma-Aldrich) were placed in 24-well microplates (Corning Inc.) for immunocytochemistry and cells were cultured at a density of $1 \times 10^{5}$ cells/well for 2 or $24 \mathrm{~h}$. Cells were fixed in 4\% paraformaldehyde for $10 \mathrm{~min}$ and were washed three times with PBS (pH 7.4). Cells were permeabilized using $0.3 \%$ Triton X-100 in PBS for 5 min. Non-specific antibody reactions were blocked with 5\% BSA in PBS for 1 h. Next, cells were incubated overnight at $4^{\circ} \mathrm{C}$ with primary mouse monoclonal antibodies diluted in PBS containing 1\% BSA. The used monoclonal mouse antibodies and dilutions were anti-nestin (10 $\mu \mathrm{g} / \mathrm{mL}$; R\&D Systems), anti-glial fibrillary acid protein (GFAP) (5 $\mu \mathrm{g} / \mathrm{mL}$; Chemicon International Inc., Billerica, MA), anti-conjugated dopamine (1:5000; Serotec, Kidlington, Oxford, UK) and anti- $\beta$-tubulin III (1:2000; Promega, Madison, WI). Cells were washed three times with PBS and incubated with secondary goat anti-mouse Fc-fluorescein isothiocyanate (1:400; Thermo Fisher Scientific, Pierce Biotechnology, Rockford, IL) for $2 \mathrm{~h}$ in the dark. Cells were incubated for $1 \mathrm{~min}$ in propidium iodide $(0.01 \mathrm{mg} / \mathrm{mL}$; Fluka, Toluca, Mexico) to counterstain the nuclei. Cells were analyzed using a fluorescence microscope (Imager Z1; Zeiss, Jena, Germany). Images were obtained using an Axiocam HRm camera system (Zeiss, New York, NY) coupled to the microscope.

\subsection{RNA Isolation and Reverse Transcription Polymerase Chain Reaction (RT-PCR)}

MSCs were cultured in six-well microplates (Corning Inc.) treated with poly-L-lysine at a density of $5 \times 10^{5}$ cells/well for 2 or $24 \mathrm{~h}$. Total RNA was isolated from undifferentiated mesenchymal cells and cells incubated in induction media using a binding silica column kit (GenElute Mammalian Total RNA; Sigma-Aldrich). The amount and quality of RNA was determined using a GeneQuant pro spectrophotometer (Amersham Biosciences, Cambridge, UK). RT-PCR was performed using a PX2 Thermo thermal cycler (Thermo Fisher Scientific), one-step reactions (Qiagen, Crawley, UK). All primers were obtained from MWG-Biotech, Huntsville, AL, USA, and are described on Table 1. 
Table 1. Primers used for RT-PCR gene detection.

\begin{tabular}{|c|c|c|}
\hline Gene & Sense & Antisense \\
\hline GAPDH & GGTGAAGGTCGGTGTGA & CATGAGCCCTTCCACGA \\
\hline En1 & TCAAAACTGACTCGCAGCA & ACTCCGCCTTGAGTCTCTGC \\
\hline Pax3 & GCCTCAGACCGACTATGCTC & CCACGGCTTACTTTGTCCAT \\
\hline Thy1.1 & CAGGGCTGCTGTCTTCCTAC & GGGCTGTCCAGTACGTCAAT \\
\hline AADC & GGATTCAGGGCTTATCACTGACTACC & TTCATTCACTTTGTTGGAACCCTTTAGC \\
\hline Aldh1 & TGTTAGCTGATGCCGACTTG & TTCTTAGCCCGCTCAACACT \\
\hline GEF10 & CAGGGCTGCTGTCTTCCTAC & GGGCTGTCCAGTACGTCAAT \\
\hline
\end{tabular}

The GAPDH gene served as an internal control. RT-PCR reactions were performed in a final volume of $50 \mu \mathrm{L}$ using $1 \mu \mathrm{g}$ of total RNA, according to the Qiagen One-Step RT-PCR protocol. Reverse transcription was performed at $50^{\circ} \mathrm{C}$ for $30 \mathrm{~min}$. PCR conditions were: activation at $95^{\circ} \mathrm{C}$ for $1 \mathrm{~min}, 35$ cycles of amplification (1 min at $94^{\circ} \mathrm{C}, 1 \mathrm{~min}$ at $60^{\circ} \mathrm{C}\left(54.6^{\circ} \mathrm{C}\right.$ for GAPDH) and $1 \mathrm{~min}$ at $72^{\circ} \mathrm{C}$ ) and $10 \mathrm{~min}$ at $72^{\circ} \mathrm{C}$ for final extension. PCR reactions were resolved on $2 \%$ agarose gels. The bands were observed under ultraviolet (UV) light and photographed in a UVP High Performance UV Transilluminator (DigiDocIt, Cambridge, UK).

\section{RESULTS}

\subsection{Immunocytochemical Detection of Neural Proteins}

Immunohistochemistry was performed to determine whether an association existed between the morphological changes observed in cells, and the expression of proteins related to neural lineages. Fluorescence microscopy analysis showed a slight positive nestin signal around the nuclei of MSCs cultured in CM (Figure 1(A)). Some MSCs incubated with IM showed a significant increase in nestin after $2 \mathrm{~h}$ of induction (Figure 1(B)). After $24 \mathrm{~h}$ of incubation in IM, most of the MSCs showed positive expression for nestin in the cytoplasm (Figure 1(C)). Immunocytochemistry for $\beta$-tubulin III showed a similar distribution: some of the MSCs incubated in CM showed a thin fibrous pattern surrounding the nucleus (Figure 1(D)). After $2 \mathrm{~h}$ in IM, most of the MSCs became positive (Figure 1(E)) and those incubated in IM for $24 \mathrm{~h}$ showed a marked increase in the fibrous pattern throughout the cytoplasm (Figure 1(F)). Immunochemistry for GFAP showed an abundant expression of the protein, even in MSCs incubated in CM (Figure 1(G)). After $2 \mathrm{~h}$, this staining became more abundant (Figure $\mathbf{1 ( H ) )}$ and after $24 \mathrm{~h}$ of incubation in IM, abundant GFAP distribution throughout the cytoplasm was observed, allowing us even to detect dendritic extensions on the cell surface as well as cell interconnections (Figure 1(I)). Do-
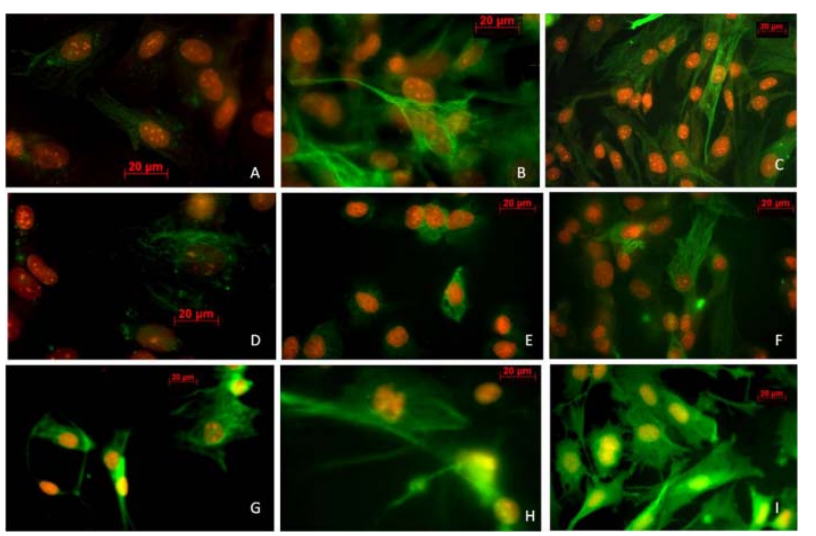

Figure 1. Immunofluorescence microscopy of MSCs cultured in control medium or induction medium. (A) Nestin detection (green) in cells incubated in control medium; (B) Cells incubated in induction medium for $2 \mathrm{~h}$ and (C) cells incubated in induction medium for $24 \mathrm{~h}$; (D) Tubulin detection (green) in cells incubated in control medium; (E) in induction medium for $2 \mathrm{~h}$ and (F) in induction medium for $24 \mathrm{~h}$; (G) Glial fibrillary acid protein (GFAP) detection in cells incubated in control medium; (H) in induction medium for $2 \mathrm{~h}$ and (I) in induction medium for $24 \mathrm{~h}$. Nuclei are counterstained with propidium iodide (red).

pamine detection was negative on MSCs cultured in CM as well as in MSCs incubated in IM for $2 \mathrm{~h}$; however, after $24 \mathrm{~h}$, the neurotransmiter was detected inside small cytoplasm vesicles (Figure 2).

\subsection{Expression of Neural Genes}

We evaluated the expression of genes for the following neural markers: Pax3, En1, GEF10 and Aldh1. Results showed positive expression for Pax3 and En1 in cells cultured in CM, as well as in IM, without apparent increases in the expression of those genes as a result of incubation in either medium. GEF10 gene expression was not detected from cells cultured in CM or IM after 2 h; however, after culture in IM for $24 \mathrm{~h}$, expression was detected. Expression of the gene for Aldh1 was not detected with any medium on cells. The cells were also ana- 


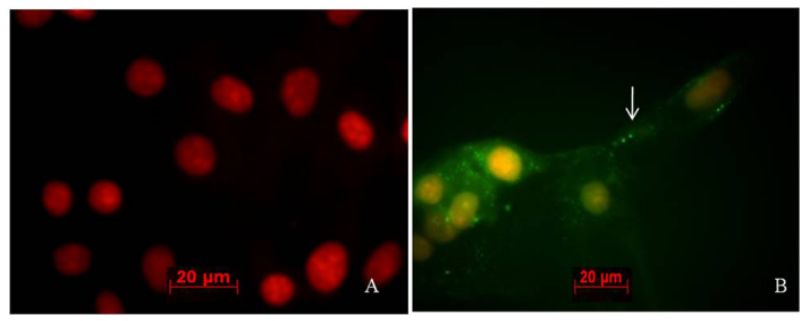

Figure 2. Immunofluorescence detection of dopamine in MSCs. (A) MSCs after $2 \mathrm{~h}$ of culture in induction medium. No dopamine was detected. Propidium iodide was used to counterstain nuclei (orange); (B) Representative images showing the presence of conjugated dopamine (green) in MSCs cultured in experimental media to induce neurodifferentiation; dopamine immunostaining appears as small vesicles (arrows) in the cytoplasm. Scale bar $=20 \mu \mathrm{m}$.

lyzed for $A A D C$ and Thy1.1 gene expression to determine whether they belonged to a dopaminergic lineage. Gel analysis showed positive expression levels for Thy1.1 in cells incubated in IM for $24 \mathrm{~h}$. AADC gene expression was negative for all media (Figure 3).

\section{DISCUSSION}

Previous studies with adult hMSCs have demonstrated that these cells express neural genes at low, nonfunctional basal levels, suggesting that they have a neural predisposition [19]. Several culture media have been proposed to induce MSCs into neuron-like cells. Those media have been supplemented with chemicals and biological growth factors, such as DMSO, SHH, FGF8 and RA. Media containing chemicals such as DMSO have raised some questions about the effective differentiation observed in terms of cell morphology. Authors claim that these morphological changes could be artifacts induced by the direct effect of this compound on the cytoskeleton [20]. Regardless of this presumption, it has been demonstrated that such changes in the cytoskeleton can stimulate the expression of neural genes [21-24]. Nevertheless, in order to avoid these possible toxic and artificial effects, DMSO concentrations included in the IM were reduced by one order of magnitude from that previously reported to induce morphological changes [20] in the present study. The IM used in our protocol also contained SHH and FGF8. It has been shown that during mammalian embryogenesis, an interaction between SHH and FGF8 induces the development of the most important dopamine-synthesizing areas: the substantia nigra and the ventral tegmental area (VTA) $[25,26]$. SHH signaling also plays a role in axonal projection of dopaminergic neurons from the substantia nigra and the VTA to rostral target tissue, which plays an essential role in mammalian motor neurons [27]. Another factor added to our IM was BDNF, which plays a role in phenotypic maturation and increases the survival of dopaminergic neurons in the

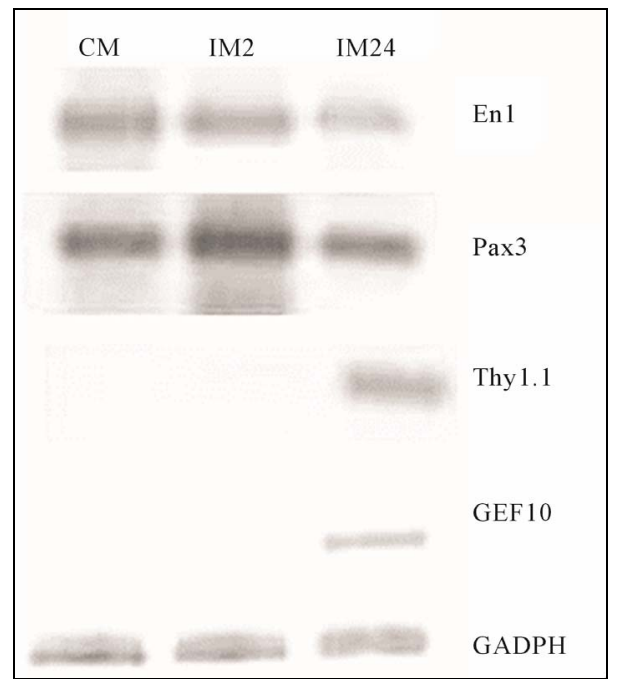

Figure 3. Reverse transcription polymerase chain reaction (RT- PCR) assays for En1, Pax3, Thy1.1, GEF10 and GAPDH expressions. (CM) RT-PCR from MSCs cultured in control medium. (IM) RT-PCR from MSCs cultured in induction medium for $2 \mathrm{~h}$ and $24 \mathrm{~h}$. En1 expression was detected in all media, as well as Pax3. Thy 1.1 and GEF10 were only detected after $24 \mathrm{~h}$ of incubation in induction medium.

developing substantia nigra $[28,29]$. This evidence infers that the presence of BDNF, SHH, and FGF8 in IM may have enhanced the expression of dopaminergic neural markers.

After $2 \mathrm{~h}$ of incubation in IM, there were some morphological changes and an increased concentration of neural markers such as GFAP, $\beta$-tubulin III, and nestin. After $24 \mathrm{~h}$ of cultivation with IM, not only those proteins showed a notable concentration increase but the expression of the genes encoding TH, GEF 10 and Pax3 were also detected. We looked for the presence of these proteins for their known participation during neuron differentiation.

Pax3 plays an important role in pattern formation in the vertebrate central nervous system and in the morphological differentiation of neural cells [30,31], as well as in the production of tyrosine hydroxylase. Tyrosine hydroxylase is the rate-limiting enzyme for dopamine synthesis in mature dopaminergic neurons [32]. GEF10 belongs to the guanine nucleotide exchange factor family and plays a role in the connectivity and morphogenesis of neural cells, including axonal growth, dendrite elaboration, plasticity, and synapse formation [33,34]. En1 maintains the survival of mature midbrain dopaminergic neurons in a terminal differentiation state during neurogenesis [35]. In this study, cells were positive for the intermediate filament, nestin, which is expressed during the early developmental stage by neural progenitor cells and downregulated upon differentiation [30,35]. This 
could reflect an ongoing stage of maturity of cells cultured in IM for $24 \mathrm{~h}$.

The presence of all of those markers indicates an immature neuronal state, which is desirable for transplantation programs, for it has been reported that immature cells could be a better therapeutic option than mature cells in allowing engraftment [36,37]. It is noteworthy that cells cultured for $24 \mathrm{~h}$ in IM showed conjugated dopamine distributed in smaller cytoplasmic inclusions detected by immunocytochemistry and this was consistent with an elevated expression of Thy1.1, according to our RT-PCR analysis. However, further research using specific markers of dopamine vesicles such as vesicular monoamine transporter 2 is required to verify whether the visualized deposits are presynaptic vesicles.

More detailed experiments are required to elucidate the pathway by which dopamine is synthesized in induced MSCs.

Aldh1 is an enzyme related to RA synthesis and is a marker of midbrain dopaminergic neurons in the late stages of fetal development and adulthood [36]. This marker was not detected in MSCs or in pre-differentiated MSCs, suggesting that these MSC-derived dopaminergic neurons did not exhibit a complete midbrain identity. However, neurogenesis in adult progenitors cannot be fully compared with developmental neurogenesis for the former is solely under environmental control whereas the latter is coordinated by morphogenetic signaling molecules produced by localized signaling centers [25].

Methods that combine chemicals with neurotrophic factors have been reported to result in the expression of neural markers, such as Tuj-1, GFAP, NSE, nestin, and NF [38]. However, these treatments require long culture times (3 - 14 d) or multistep differentiation protocols. In the present study, cells incubated in our medium allowed us to obtain immature dopaminergic cells in a short time (48 h), representing an advantage for autologous or heterologous transplantation procedures in terms of eliminating excessive manipulation of cells and prolonged culture times.

\section{CONCLUSION}

Although further studies are needed to verify its full efficacy in animal model, the results are encouraging for the use of pre-differentiated MSCs, as a possible alternative for Parkinson's disease cell therapy.

\section{ACKNOWLEDGEMENTS}

This work was partially funded by endowments from ITESM (cat-134) and the Zambrano-Hellion Foundation. The funders had no role in study design, data collection and analysis, decision to publish, or preparation of the manuscript. No additional external funding was received for this study. The authors express their appreciation to Rosa Maria de la Rosa for technical assistance.

\section{REFERENCES}

[1] Mizuno, Y., Hattori, N., Kubo, S., et al. (2008) Progress in the pathogenesis and genetics of Parkinson's disease. Philosophical Transactions of the Royal Society B: Biological Sciences, 363, 2215-2227.

doi:10.1098/rstb.2008.2273

[2] Savitt, J.M., Dawson, V.L. and Dawson, T.M. (2006) Diagnosis and treatment of Parkinson disease: Molecules to medicine. Journal of Clinical Investigation, 116, 1744-1754. doi:10.1172/JCI29178

[3] Bjorklund, L.M., Sánchez-Pernaute, R., Chung, S., et al. (2002) Embryonic stem cells develop into functional dopaminergic neurons after transplantation in a Parkinson rat model. Proceedings of the National Academy of Sciences of the United States of America, 99, 2344-2349. doi:10.1073/pnas.022438099

[4] Cho, Y.H., Kim, D.S., Kim, P.G., Hwang, et al. (2006) Dopamine neurons derived from embryonic stem cells efficiently induce behavioral recovery in a Parkinsonian rat model. Biochemical and Biophysical Research Communications, 341, 6-12. doi:10.1016/j.bbrc.2005.12.140

[5] Mine, Y., Hayashi, T., Yamada, M., Okano, H. and Kawase, T. (2009) Environmental cue-dependent dopaminergic neuronal differentiation and functional effect of grafted neuroepithelial stem cells in parkinsonian brain. Neurosurgery, 65, 741-753.

doi:10.1227/01.NEU.0000351281.45986.76

[6] Ben-Hur, T., Idelson, M., Khaner, H., et al. (2004) Transplantation of human embryonic stem cell-derived neural progenitors improves behavioral deficit in Parkinsonian rats. Stem Cells, 22, 1246-1255. doi:10.1634/stemcells.2004-0094

[7] Freed, C.R., Greene, P.E., Breeze, R.E., et al. (2001) Transplantation of embryonic dopamine neurons for severe Parkinson's disease. New England Journal of Medicine, 344, 710-719. doi:10.1056/NEJM200103083441002

[8] Kordower, J.H., Freeman, T.B., Snow, B.J., et al. (1995) Neuropathological evidence of graft survival and striatal reinnervation after the transplantation of fetal mesencephalic tissue in a patient with Parkinson's disease. New England Journal of Medicine, 332, 1118-1124. doi:10.1056/NEJM199504273321702

[9] Brundin, P., Pogarell, O., Hagell, P., et al. (2000) Bilateral caudate and putamen grafts of embryonic mesencephalic tissue treated with lazaroids in Parkinson's disease. Brain, 123, 1380-1390. doi:10.1093/brain/123.7.1380

[10] Piccini, P., Pavese, N., Hagell, P., et al. (2005) Factors affecting the clinical outcome after neural transplantation in Parkinson’s disease. Brain, 128, 2977-2986. doi:10.1093/brain/awh649

[11] Chu, Y., \& Kordower, J.H. (2010) Lewy body pathology in fetal grafts. Annals of the New York Academic of Science, 1184, 55-67. doi:10.1111/j.1749-6632.2009.05229.x 
[12] Li, J.Y., Englund, E., Widner, H., et al. (2010) Characterization of lewy body pathology in 12- and 16-year-old intrastriatal mesencephalic grafts surviving in a patient with Parkinson's disease. Movement Disorder, 25, 10911096. doi:10.1002/mds.23012

[13] Vierbuchen, T., Ostermeier, A., Pang, Z.P., Kokubu, Y., Südhof, T.C. and Wernig, M. (2010) Direct conversion of fibroblasts to functional neurons by defined factors. $\mathrm{Na}$ ture, 463, 1035-1041. doi:10.1038/nature08797

[14] Pfisterer, U., Kirkeby, A., Torper, O., et al. (2011) Direct conversion of human fibroblasts to dopaminergic neurons. Proceedings of the National Academy of Sciences of the United States of America, 108, 10343-10348. doi:10.1073/pnas.1105135108

[15] Pang, Z.P., Yang, N., Vierbuchen, T., et al. (2011) Induction of human neuronal cells by defined transcription factors. Nature, 476, 220-223. doi:10.1038/nature10202

[16] Blandini, F., Cova, L., Armentero, M.T., et al. (2010) Transplantation of undifferentiated human mesenchymal stem cells protects against 6-hydroxydopamine neurotoxicity in the rat. Cell Transplantation, 19, 203-217. doi:10.3727/096368909X479839

[17] Khoo, M.L., Tao, H., Meedeniya, A.C., Mackay-Sim, A. and Ma, D.D. (2011) Transplantation of neuronal-primed human bone marrow mesenchymal stem cells in hemiparkinsonian rodents. PLoS One, 6, e19025. doi:10.1371/journal.pone.0019025

[18] Binato, R., de Souza Fernandez, T., Lazzarotto-Silva, C., et al. (2013) Stability of human mesenchymal stem cells during in vitro culture: Considerations for cell therapy. Cell Proliferation, 46, 10-22. doi:10.1111/cpr.12002

[19] Montzka, K., Lassonczyky, N., Tshöke, B., et al. (2009) Neural differentiation potential of human bone marrowderived mesenchymal stromal cells. BMC Neuroscience, 10, 16. doi:10.1186/1471-2202-10-16

[20] Lu, P., Blesch, A. and Tuszynski, M. (2004) Induction of bone marrow stromal cells to neurons: Differentiation, transdifferentiation or artifact? Journal of Neuroscience Research, 77, 174-191. doi:10.1002/jnr.20148

[21] Croft, A. and Przyborski, S. (1999) Formation of neurons by non-neural adult stem cells: Potential mechanism implicates an artifact of growth in culture. Stem Cells, 24, 1841-1851. doi:10.1634/stemcells.2005-0609

[22] Ren, X.D., Kiosses, W.B. and Schwartz, M.A. (1999) Regulation of the small GTP binding protein Rho by cell adhesion and the cytoskeleton. EMBO Journal, 18, 578585. doi:10.1093/emboj/18.3.578

[23] Yujiri, T., Fanger, G.R., Garrington, T.P., Schlesinger, T.K., Gibson, S. and Johnson, G.L. (1999) MEK kinase 1 (MEKK1) transduces c-Jun NH2-terminal kinase activetion in response to changes in the microtubule cytoskeleton. Journal of Biological Chemistry, 274, 12605-12610. doi:10.1074/jbc.274.18.12605

[24] Subbaramaiah, K., Hart, J.C. and Norton, L. (2000) Dannenberg AJ Microtubule-interfering agents stimulate the transcription of cyclooxygenase-2. Evidence for involvement of RK1/2 AND p38 mitogen-activated protein kinase pathways. Journal of Biological Chemistry, 275,
14838-14845. doi:10.1074/jbc.275.20.14838

[25] Gale, E. and Li, M. (2008) Midbrain dopaminergic neuron fate specification: Of mice and embryonic stem cells. Molecular Brain, 1, 8. doi:10.1186/1756-6606-1-8

[26] Björklund, A. and Dunnett, S. (2007) Dopamine neuron systems in the brain: An update. Trends in Neuroscience, 30, 194-202. doi:10.1016/j.tins.2007.03.006

[27] Hammond, R., Blaes, S. and Abeliovich, A. (2009) Sonic hedgehog is a chemoattractant for midbrain dopaminergic axons. PLoS One, 4, e7007. doi:10.1371/journal.pone.0007007

[28] Hyman, C., Hofer, M., Barde, Y., et al. (1991) BDNF is a neutrophic factor for dopaminergic neurons of the substantia nigra. Nature, 350, 230-232. doi:10.1038/350230a0

[29] Volpicelli, F., Caiazzo, M., Greco, D., et al. (2007) BDNF gene is a downstream target of Nurr1 transcription factor in rat midbrain neurons in vitro. Journal of Neurochemistry, 102, 441-453. doi:10.1111/j.1471-4159.2007.04494.x

[30] Bang, A., Papalopulu, N., Kintner, C. and Goulding, M. (1997) Expression of Pax3 is initiated in the early neural plate by posteriorizing signals produced by the organizer and by posterior non-axial mesoderm. Development, 124, 2075-2085.

[31] Goulding, M., Chalepakis, G., Deutsch, U., Erselius, J.R. and Gruss, P. (1991) Pax3, a novel murine DNA-binding protein expressed during early neurogenesis. EMBO Journal, 10, 1135-1147.

[32] Daubner, S.C., Le, T. and Wang, S. (2011) Tyrosine hydroxylase and regulation of dopamine synthesis. Archieves of Biochemistry and Biophysics, 508, 1-12. doi:10.1016/j.abb.2010.12.017

[33] Verhoeven, K., Jonghe, P., Putte, T., et al. (2003) Slowed conduction and thin myelination of peripheral nerves associated with mutant Rho guanine-nucleotide exchange factor 10. American Journal of Human Genetics, 73, 926932. doi:10.1086/378159

[34] Schmidt, A. and Hall, A. (2002) Guanine nucleotide exchange factors for Rho GTPases: Turning on the switch. Genes and development, 16, 1587-1609. doi:10.1101/gad.1003302

[35] Michalczyk, K. and Ziman, M. (2005) Nestin structure and predicted function in cellular cytoskeletal organisation. Histology and histopathology, 20, 665-671.

[36] Canola, K., Angenieux, B., Tekaya, M., et al. (2007) Retinal stem cells transplanted into models of late stages of retinitis pigmentosa preferentially adopt a glial or a retinal ganglion cell fate. Investigative ophthalmology and visual science, $\mathbf{4 8}$, 446-454. doi:10.1167/iovs.06-0190

[37] MacLaren, R.E., Pearson, R.A., MacNeil, A. et al. (2006) Retinal repair by transplantation of photoreceptor precursors. Nature, 444, 203-207. doi:10.1038/nature05161

[38] Sanchez-Ramos, J., Song, S., Cardozo-Pelaez, F., et al. (2000) Adult bone marrow stromal cells differentiate into neural cells in vitro. Experimental Neurology, 164, $247-$ 256. doi:10.1006/exnr.2000.7389 